See discussions, stats, and author profiles for this publication at: https://www.researchgate.net/publication/341209932

\title{
Tax on Cryptocurrency as Innovative Financial Instrument in IT Sphere
}

Article in International Journal of Advanced Trends in Computer Science and Engineering · April 2020

DOI: 10.30534/ijatcse/2020/4191.22020

CITATION

1

2 authors:

C... Oleg Reznik

Sumy State University

10 PUBLICATIONS 20 CITATIONS

SEE PROFILE
READS

88

Nadiia Andriichenko

Sumy State University

12 PUBLICATIONS 16 CITATIONS

SEE PROFILE

Some of the authors of this publication are also working on these related projects:

Assessment of law enforcement agencies' activity as subjects ensuring financial and economic security of the state View project 


\title{
International Journal of Advanced Trends in Computer Science and Engineering
}

Available Online at http://www.warse.org/IJATCSE/static/pdf/file/ijatcse4191.22020.pdf https://doi.org/10.30534/ijatcse/2020/4191.22020

\section{Tax on Cryptocurrency as Innovative Financial Instrument in IT Sphere}

\author{
Oleg Reznik ${ }^{1}$, Nadiia Andriichenko ${ }^{2}$, Mykola Inshyn ${ }^{3}$, Nataliya Maslak ${ }^{4}$, Olena Arsentieva ${ }^{5}$ \\ ${ }^{1}$ Doctor of Juridical Sciences, Associate Professor of the Department of Administrative, Economic Law and \\ Economic Security, Educational and Research Institute of Law, Sumy State University, Ukraine, \\ o.reznik@yur.sumdu.edu.ua \\ ${ }^{2}$ Postgraduate student of the Department of Administrative, Economic Law and Economic Security, Educational \\ and Research Institute of Law, Sumy State University, Ukraine \\ ${ }^{3}$ Doctor of Juridical Sciences, Professor, Academician of the National Academy of Science of Ukraine, Honored \\ Lawyer of Ukraine, Taras Shevchenko National University of Kyiv, Ukraine \\ ${ }^{4} \mathrm{PhD}$ in Law, Assistant of the Criminal Law Department, Yaroslav Mudryi National Law University, Kharkiv, \\ Ukraine \\ ${ }^{5} \mathrm{PhD}$ in Law, Associate Professor, Dean of the Faculty of Law, Volodymyr Dahl East Ukrainian National \\ University, Severodonetsk, Ukraine
}

\begin{abstract}
The article deals with the content of the tax on cryptocurrency, which is an innovative IT instrument of economic development. It has been established that there was no common understanding of the official status of cryptocurrency given that each state establishes it in the framework of its national legislation independently, and the introduction of taxes is one of the instruments of state influence on the cryptocurrency circulation. It has been found out that the EU member states had only one restriction on the taxation of cryptocurrency, namely cryptocurrency transactions were not liable for VAT. Foreign experience in taxing cryptocurrency transactions is considered in the article. It has been established that Ukraine offered the most optimal tax rate on income from cryptocurrency transactions for individuals and legal entities. At the same time, the significance of the economic effect of the cryptocurrency tax in the form of revenues to the state budget due to the unstable cryptocurrency exchange rate is disproved, which raises the issue of the feasibility of search for new areas of state influence on cryptocurrency.
\end{abstract}

Key words: cryptocurrency, cryptocurrency transactions, income tax, IT instrument.

\section{INTRODUCTION}

The development of the economy of any state is impossible without creating favorable conditions for the realization of the economic interests of all stakeholders. Today, one of such entities is individuals and legal entities that carry out cryptocurrency transactions to obtain the main or additional income. For a long time, cryptocurrency has not been something new for the global economy, something which could force authorities of the states worldwide to pay significant attention to creating a legal framework for mining, buying and selling, exchanging and carrying out other transactions with cryptocurrency. This is caused both by the development of digital technologies and by the characteristics of cryptocurrency, which can be used as a tool of illegal activity. At the same time, the states should find such a mechanism for the legal regulation of cryptocurrency turnover that will allow it to be used to gradually attract investment in the state economy.

One of the means for the legal regulation of cryptocurrency turnover is undoubtedly the taxation of cryptocurrency transactions. Despite the importance of taxing cryptocurrency transactions, the countries of the European Union have only agreed on the need to exempt cryptocurrency transactions from VAT. Accordingly, each of the European Union states retains the freedom to determine tax rates for cryptocurrency transactions at its own discretion. Besides, the scientists proved that it is a core element of macroeconomic stability [1], [2]. At first glance, this situation seems to be favorable, but it is advisable to establish cooperation between states to develop a single legal framework for cryptocurrency transactions and minimize the risks that it carries.

\section{LITERATURE REVIEW}

The gradual transition to a new model of economic development implies more intensive use of new digital technologies. Venkata Marella, Bikesh Upreti, Jani Merikivi, Virpi Kristiina emphasize that cryptocurrency is based on basic technologies that enable transactions, while cryptocurrencies lack the institutional support of central government. However, the use of cryptographic methods increases the confidence of users in cryptocurrency, although traditional financial instruments benefit from institutional support. At the same time, cryptocurrency requires trust not in 
people, but in technologies that ensure the security of a financial transaction [3]. Gil-Alana L.A., Abakah E.J.A. and Rojo M.F.R. [4] emphasize that cryptocurrency holds a significant place in investor portfolios. Since they allow diversifying their investment assets, this confirms that cryptocurrency is a new class of investment assets. The success of investment activity depends on the spread $\mathrm{f}$ information [5]-[6].

Chatterjee G., Edla D.R. and Kuppili V. emphasize that cryptocurrency research almost always deals with studying the turnover of BitCoin, and only some scientists pay attention to the existence of other types of cryptocurrency. Indeed, BitCoin holds the first place in the list of cryptocurrencies, but Ethereum, Litecoin varieties of cryptocurrencies are equally common [7]. The popularization of cryptocurrency in the global and national financial markets has updated the research on the risks of cryptocurrency turnover, the tools used by the state to influence cryptocurrency to minimize potential risks, while the list of issues that are of interest to scientists is not exhaustive. In particular, cryptocurrency is actively used to finance terrorism. At the same time, such terrorist acts can affect the financial operations of the state, the value of securities and the investment climate, significantly reduce tax revenues, and adversely affect the state and society as a whole [8]. This requires existing law enforcement agencies to act more effectively, responding promptly to any new threats to the financial interests of the state [9]. Accordingly, the settlement of the issue of cryptocurrency turnover, according to Panova G.S. [10], is a key issue of international cooperation. In the context of the global information space [11]-[12], the first steps to achieve a balance of currency relations is the development of national currency systems based on national digital currencies and their gradual integration into the global currency system in the future [10]. It should also be acknowledged that the national level is not the level where efforts to combat money laundering, terrorist financing, tax evasion and fees through cryptocurrency transaction should be consolidated, as cryptocurrency transactions have no specific boundaries. Therefore, not even a European, but an international level is more suitable since the cryptocurrency is not limited by the European border. International cooperation in the context of the United Nations Office on Drugs and Crime, the FATF and the Egmont Group is, therefore, a key to minimizing the use of cryptocurrency in illegal activities [13]. Another way of minimizing the negative impact of cryptocurrency on the global economy and using only its advantages, according to Efremenko I.N., Panasenkova T.V., Artemenko D.A., Larionov V.A., is the provision of cryptocurrency with international status since the dynamics of cryptocurrency turnover is quite positive [14]. This position immediately became debatable. In particular, James Surowiecki argues that granting cryptocurrency the status of a dominant currency could significantly destabilize the economic situation in states, and authorities would be powerless under such conditions due to the limited tools to influence the cryptocurrency turnover [15]. The situation may become even more complicated in states where the level of political corruption significantly impedes the work of the state apparatus [16]. However, one should agree with White R., Marinakis Y., Islam N. and Walsh S. who note that, first, it is necessary to narrow the status of the cryptocurrency, although there is no unequivocal opinion on whether the official status of the cryptocurrency as a currency, security, derivative, money transfer tool would minimize all risks that it entails [17].

\section{MATERIALS AND METHODS}

Official empirical data were used to study cryptocurrency as an innovative financial instrument. They were generalized and analyzed to have a better understanding of the problem of taxation of cryptocurrency transactions. In addition, a number of methods contributed to the achievement of the research objective, in particular, the comparative method allowed revealing the existing approaches to the taxation of cryptocurrencies in states in order to create a favorable investment climate; the abstract logical method was used to generalize the obtained material, to form logical presentation, and provide conclusions of the research.

\section{RESULTS AND DISCUSSION}

Galanov V.A., Perepelitsa D.G., Galanova A.V., Chelukhina N.F. and Asyeva E.A. state that it is possible to avoid the potential risks of cryptocurrency only if the cryptocurrency market is formed under the regulatory influence of the state [18]. The complexity of officially recognizing and regulating the turnover of cryptocurrency with the currently available tools, as noted by Cocco L., Tonelli R. and Marchesi M., is due to the lack of the required infrastructure that differs from the traditional financial system of the state [19]. Creating a legal framework for the cryptocurrency turnover, state authorities should understand that the anonymity and decentralized nature of cryptocurrency create all the conditions for using it in illegal activity [20]-[22].

In turn, the instruments for the legal regulation of cryptocurrency turnover should be taxation of cryptocurrency transactions and income received from transactions [23], as well as the introduction of restrictions and prohibitions on certain cryptocurrency transactions, the introduction of monitoring the legality of such transactions, the development of a procedure for obtaining a license to carry out activities directly or indirectly associated with cryptocurrency [24].

However, Ram A.J. emphasizes that the taxation of traditional currency and cryptocurrency has significant differences, primarily because cryptocurrency transactions are exchange transactions, which is the basis for state tax 
control over cryptocurrency transactions [25]. Therefore, according to Svitlana Volosovych and Yurii Baraniuk, there is a risk that developing a tax control mechanism for cryptocurrency transactions will at the same time create conditions for the identification of entities and objects of cryptocurrency transactions thus complicating the legitimization of cryptocurrency transactions in the economy. However, the liberal model of regulation of the cryptocurrency market, as well as the repressive model, are not so common in the world. Examples of the liberal model are Belarus and Denmark, while repressive models are found in Algeria, Vietnam, Indonesia, Kyrgyzstan, Morocco, and Nepal. At the same time, most countries are drafting laws to regulate the cryptocurrency turnover, in particular, they are countries that use a wide range of administrative and financial methods, including taxation of cryptocurrency transactions, such as Australia, the United Kingdom, Israel, Canada, the Netherlands, Germany, Norway, Singapore, the United States, Finland, and Japan.

Instead, Ukraine has not developed a single approach to determining the status of cryptocurrency. This is evidenced by the fact that, according to the position of the National Bank of Ukraine, this is a virtual currency, the 2017 draft law On Cryptocurrency Turnover emphasized that this is a program code, which is the subject of property rights, another 2017 draft law On Incentivization of Market of Cryptocurrencies and Their Derivatives defined cryptocurrency as a decentralized digital measurement of value that is numerically expressed and functions as a means of exchange, storage, or unit of account based on mathematical calculations, is their result and has cryptographic accounting protection. In the individual tax consultation No. 282/K/99-99-13-01-02-14/IPK On the Procedure of Taxation of Income of Some Transactions submitted on January 25, 2019, the State Fiscal Service of Ukraine concluded that the nature of cryptocurrency did not give reasonable grounds for recognizing it as money, electronic money or a monetary surrogate, currency or currency value, means of payment of other states or securities.

Despite the fact that cryptocurrency does not have official status, the Ukrainian legislator made attempts to legislatively regulate the taxation of cryptocurrency transactions. Thus, the 2017 draft law On Amendments to the Tax Code of Ukraine (on Incentivizing Cryptocurrency and Its Derivatives in Ukraine) proposed to exempt enterprises (except financial institutions providing financial services in the cryptocurrency market in accordance with the Law of Ukraine On Incentivizing Market of Cryptocurrency and Its derivatives in Ukraine) from the income tax on cryptocurrency transactions. In 2019, a new draft law On Amending the Tax Code and Other Laws of Ukraine Regarding the Taxation of Transactions with Crypto Assets was registered in parliament. Already proceeding only from the name of the draft law, it is obvious that in Ukraine the concept of "cryptocurrency" should be replaced by "crypto asset". This regulatory act should create the legal field for the turnover of crypto assets. The object of taxation in this case is the profit from operations with crypto assets, i.e. the positive difference between the income received by the entity from the sale of crypto assets and the costs associated with their acquisition or creation. General tax rate for corporate income from operations should be $18 \%$ (Article 136.1 of the Tax Code of Ukraine).

It stipulates that individuals who receive investment income from the sale of crypto assets should pay a tax of 5\%, while transactions for the sale of crypto assets should be exempt from VAT. The above is fully consistent with the decision of the European Court as of October 22, 2015, according to which the exchange of traditional currency for BitCoin should be exempt from VAT, since the European Union prohibit the collection of such tax from the exchange of currency, banknotes and coins. Herewith, the 2019 draft law does not mention the tax on the profits of legal entities received from transactions with crypto assets. Moreover, it remains unclear how the initial and final value of crypto assets should be confirmed, since there are no indications of specific documents. Thus, the draft law On Amendments to the Tax Code and Other Laws of Ukraine on Taxation of Cryptocurrency Transactions does not create any opportunities for legal entities engaged in cryptocurrency transactions.

Another new rule that we propose to consolidate at the level of national legislation is criminal liability for tax evasion from income derived from cryptocurrency transactions under Article 212 of the Criminal Code of Ukraine, including the possibility of applying a fine ranging from 17,000 to $425,000 \mathrm{UAH}$ and confiscation of property. In cases where there are no grounds for criminal liability, a penalty of $25 \%$ of the hidden amount of tax may be imposed, as well as a fine, i.e. the application of financial liability.

In Denmark and Switzerland, as indicated by Kjaersgaard L.F. and Arfwidsson A., most cryptocurrencies are subject to tax on assets held for investment and other commercial purposes. However, according to scientists, this approach to taxation creates a significant barrier to realizing the economic potential of cryptocurrencies in the country. Moreover, the classification of cryptocurrencies by type creates problems and ambiguities for the purposes of taxing cryptocurrency, since it would be more correct for each type of cryptocurrency to have its own tax mechanism, given their somewhat different characteristics [26].

In view of the foregoing, it should be noted that the introduction of taxes on profits from cryptocurrency transactions is one of the means of publicly influencing them for legitimate purposes, in a transparent and open manner. At the same time, the situation is complicated by the fact that each state independently determines the status of the cryptocurrency and the general principles of operations with 
it from a complete ban to the absence of any restrictions, including tax obligations. At the same time, given the opinions of scientists, it is still debatable whether taxing cryptocurrency transactions is a tool that will attract additional funds to the budget, attract investors and make cryptocurrency trading open and transparent.

\section{EXPERIMENTAL}

As of 2019, the market capitalization of cryptocurrencies in the world was $\$ 212.589$ billion. According to scientists, about $31 \%$ of all cryptocurrency transactions are in the European region (Fig. 1), so the efforts of states to create a legal framework for its implementation, including the introduction of elements of tax control is appropriate and necessary under current conditions. However, some states create additional conditions for the legal implementation of cryptocurrency transactions by refusing to tax them.

Belarus became one of the countries where cryptocurrency was legalized in 2017. According to the Decree of the President of the Republic of Belarus On the Digital Economy Development No. 8 as of December 21, 2017, legal transactions involving the sale, cash transfer and exchange of cryptocurrency can be carried out at banks. Moreover, it is possible to trade Bitcoin futures without charging and paying taxes and fees. At the same time, in order to avoid abuse of the capabilities of the cryptocurrency, taking into account its characteristics, they have obliged cryptocurrency exchanges where operations with the cryptocurrency are carried out to provide information about the ultimate owners of the cryptocurrency [28]. In addition, until January 1, 2023, all cryptocurrency transactions are exempt from taxation, which should help attract investors to the economy of the Republic of Belarus. In order to minimize the anonymity of cryptocurrency, in South Korea, individuals who make transactions with or receive income from cryptocurrency are obliged to use traditional banking services and indicate their real name when conducting transactions with cryptocurrency, and banks are legally responsible for keeping records of such transactions.

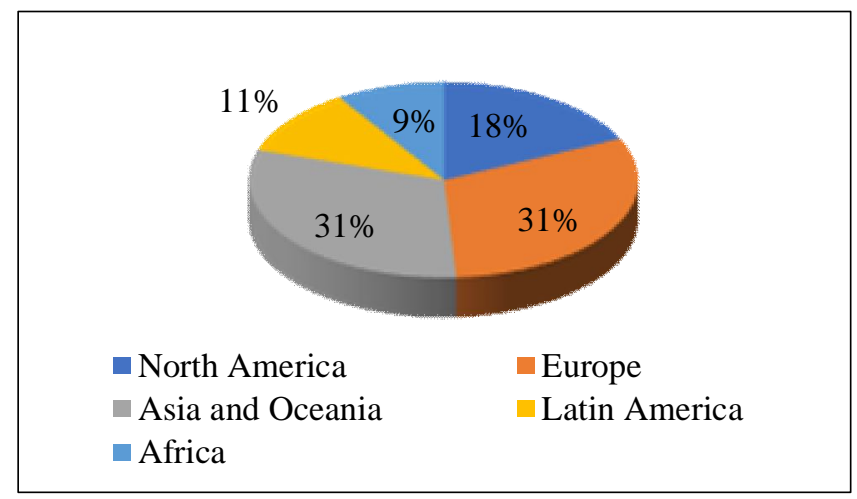

Figure 1: Percentage of cryptocurrency payments by region of the world (built using data [27])
Japan has more advanced experience. Since 2017, when the relevant law was adopted, the cryptocurrency has received official status of "non-cash payment". The Financial Services Agency has been set up to control virtual currency transactions. Accordingly, each cryptocurrency transaction will be officially documented. Moreover, companies that intend to formally perform cryptocurrency transactions or provide the relevant services must fulfill several requirements: first, their account must have a reserve currency of at least $\$ 100,000$, and, second, upon receipt of the license, the amount of $\$ 300,000$ must be paid once. This contribution helps cover the potential risks of cryptocurrency transactions. At the same time, in case of refusal to issue a license for cryptocurrency transactions, the entities shall not be refunded the amount of the one-time payment paid to them [29].

In the Republic of Poland, cryptocurrency is recognized as a digital representation of assets that are not issued by a central bank, credit institution or electronic money organization and that can, under certain conditions, be used as an alternative to money. Cryptocurrency transactions are subject to income tax in accordance with the laws of the Republic of Poland [30]. Cryptocurrency transactions in other countries, namely France, Belgium, Israel, Spain, Japan, and Bulgaria are also taxed on profits (Fig. 2).

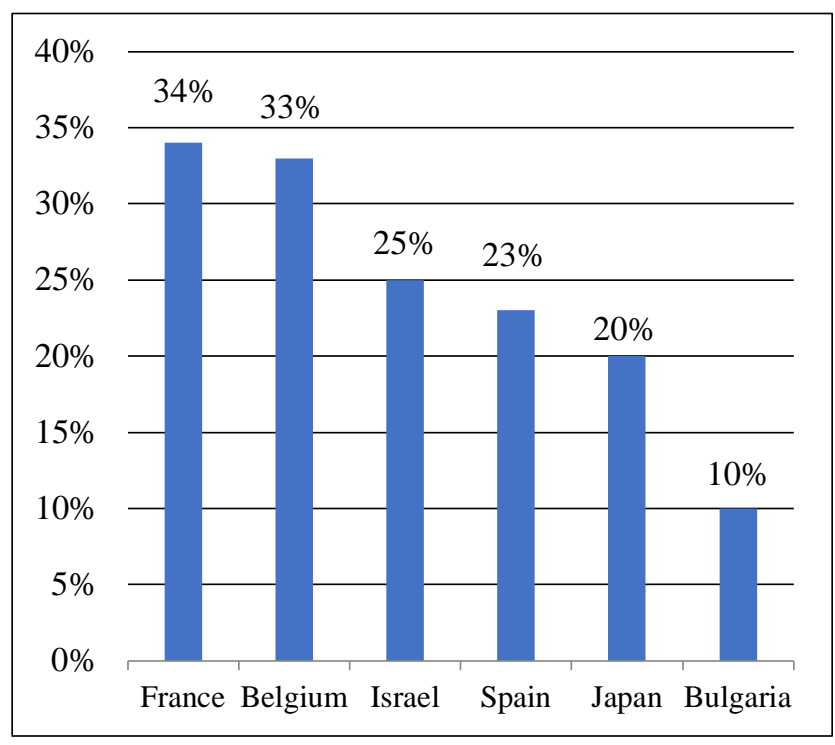

Figure 2: Rate of tax on personal income from cryptocurrency transactions

Compared to other countries, the proposed tax rate of 5\% in Ukraine will be paid by natural persons from the amount of investment income received from crypto-asset transactions and $18 \%$ from the profit from crypto-asset transactions for legal entities is moderate. However, there are some points that suggest that the innovations will not significantly increase the state budget revenues and will not attract investors.

Thus, according to preliminary expert data, the income tax on cryptocurrency should attract about $\$ 10$ million to the state 
Oleg Reznik et al., International Journal of Advanced Trends in Computer Science and Engineering, 9(1.2), 2020, 243 - 249

budget of Ukraine. However, it should be kept in mind that it is difficult to calculate the amount of funds raised because of the constant volatility of the value of cryptocurrency. As noted by Aleksander Berentsen and Fabian Schär, it prevents the impact of government financial instruments used to stabilize the national currency against foreign currencies, regulate expenditures and budget revenues [31]. Today, the most common cryptocurrency with which transactions are carried out is BitCoin (Fig. 3), however, the value of other cryptocurrencies cannot be ignored. In particular, on June 22, 2019, the core cryptocurrency exchange rate was as follows: BitCoin - \$10,842, Ethereum - \$310, BitCoin Cash - \$481, Litecoin - \$43, while on June 25, 2019 the value of cryptocurrencies changed: BitCoin - $\$ 11,245$, Ethereum $\$ 309$, BitCoin Cash $-\$ 468$, Litecoin $-\$ 132$. Such instability does not allow cryptocurrency to become a stable value that can be used for cash and non-cash payments.

It is worth noting that such instability affects investors' interest in investing in the crypto industry. According to CB Insights, 227 deals totaling $\$ 784$ million were concluded in 2019. For comparison, in 2018, global companies raised about $\$ 4.1$ billion in venture capital investments. The interest of large corporations in the cryptocurrency is declining substantially (Fig. 4).

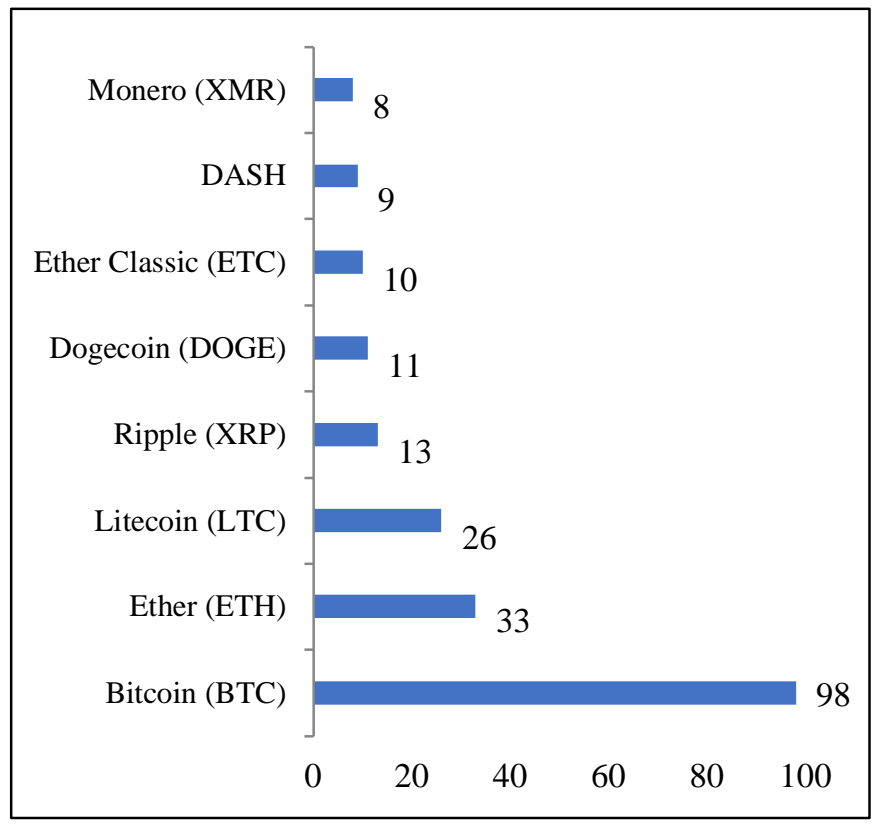

Figure 3: Percentage of cryptocurrency transactions by type in the global market

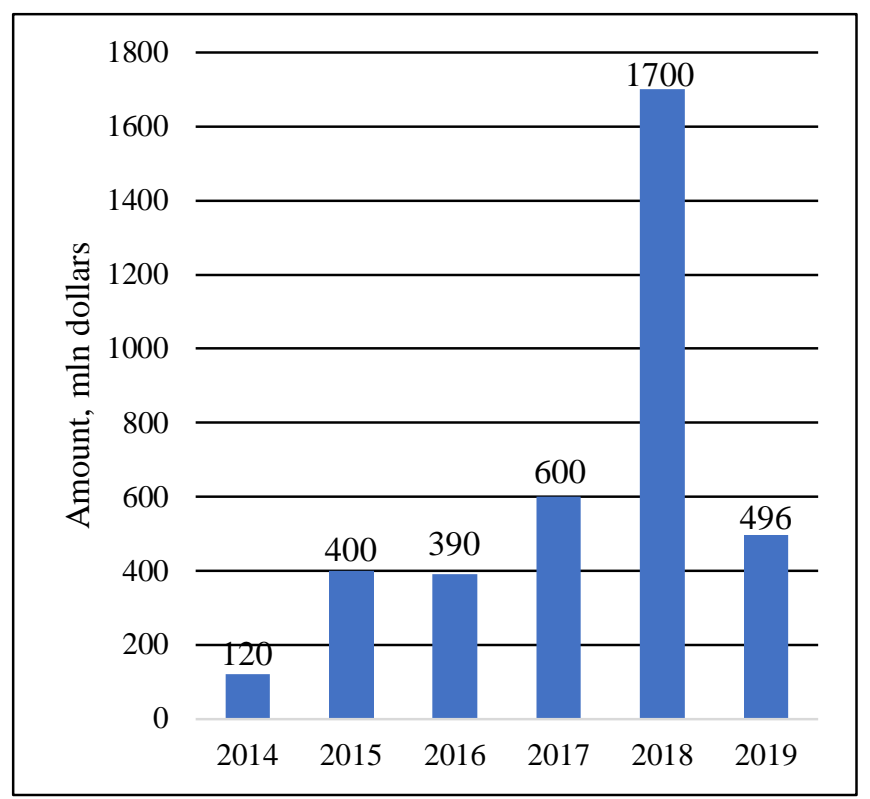

Figure 4: The amount of transactions with cryptocurrency by corporate companies from 2014 to 2019 (built according to data [32])

Thus, it is not feasible to predict the specific economic effect of introducing a cryptocurrency tax in the form of additional revenues to the state budget, attracting investments to Ukraine due to the unstable cryptocurrency rate, which affects the interest of large companies in investing in cryptocurrency. This, in turn, only increases the relevance of the search for other areas of government influence on cryptocurrency.

\section{CONCLUSION}

The development of digital technology has led to the development of cryptocurrency. The issue of cryptocurrency today is one of the urgent for individual states and relevant regional unions. One of such issues is the creation of conditions for the cryptocurrency transactions to be shadowed. In this connection, states at the national level independently determine the status of cryptocurrencies, introduce elements of tax control over cryptocurrency transactions. In Ukraine, since 2017, no draft law proposing to amend the Tax Code of Ukraine has been adopted. The latest draft law, in particular, provides for a rate of $18 \%$ of corporate income tax on cryptocurrency transactions, while rate of 5\% is suggested for individuals. These proposals can make certain operations with cryptocurrency transactions transparent, moreover, compared with other countries (France, Belgium, Israel, Spain, Japan, Bulgaria) rates of $18 \%$ and $5 \%$ for income from cryptocurrency transactions are low. The Republic of Belarus generally temporarily exempts cryptocurrency transactions from any taxation. Nevertheless, to predict the specific economic effect of the introduction of a cryptocurrency tax in the form of specific amounts of revenues to the state budget is erroneous due to the unstable cryptocurrency exchange rate and, accordingly, it is feasible 
Oleg Reznik et al., International Journal of Advanced Trends in Computer Science and Engineering, 9(1.2), 2020, 243 - 249

to search for new areas of state influence on cryptocurrency, its use in the interests of the state and society.

\section{ACKNOWLEGEMENT}

The study of this topic can become the basis for further scientific research and introducing amendments to the legislation of Ukraine in terms of determining the mechanism of state influence on the cryptocurrency turnover in the state as innovative IT instrument.

\section{REFERENCES}

[1] Y. Bilan., A.G. Raišienė, T. Vasilyeva, O. Lyulyov, and T. Pimonenko. Public governance efficiency and macroeconomic stability: Examining convergence of social and political determinants. Public Policy and Administration, 18(2), pp. 241-255, 2019 doi:10.13165/VPA-19-18-2-05.

[2] Y. Bilan, T. Vasilyeva, O. Lyulyov, and T. Pimonenko. (2019). EU vector of ukraine development: Linking between macroeconomic stability and social progress. International Journal of Business and Society, 20(2), pp. 433-450, 2019.

[3] M. Venkata, U. Bikesh, M. Jani, and K. T. Virpi. Understanding the creation of trust in cryptocurrencies: the case of Bitcoin. Electronic Markets, 2020. DOI: https://doi.org/10.1007/s12525-019-00392-5.

[4] L.A Gil-Alana, E.J.A. Abakah, M.F.R. Rojo. Cryptocurrencies and stock market indices. Are they related? Research in International Business and Finance, 2020. DOI: 10.1016/j.ribaf. 2019.101063.

[5] S. Leonov, S. Frolov, and V. Plastun. (2014). Potential of institutional investors and stock market development as an alternative to households' savings allocation in banks. Economic Annals-XXI, Vol. 11-12, pp. 65-68, 2014.

[6] Y. Bilan, S. Lyeonov, T. Vasylieva., and Y. Samusevych. Does tax competition for capital define entrepreneurship trends in Eastern Europe? Online Journal Modelling the New Europe, Vol. 27, pp. 34-66, 2018. doi:10.24193/OJMNE.2018.27.02.

[7] G. Chatterjee, D.R. Edla, V Kuppili. Cryptocurrency: A Comprehensive Analysis. Smart Innovation, Systems and Technologies, 2020. DOI: 10.1007/978-981-15-0077-0_37

[8] A. Andrianova. Countering the financing of terrorism in the conditions of digital economy. Advances in Intelligent Systems and Computing, 2020. DOI: 10.1007/978-3-030-11367-4_2.

[9] O.O. Vakulyk, N.S. Andriichenko, O.M. Reznik, V.V. Volik, K.D. Yanishevska. (2019) International aspect of a legal regulation in the field of financial crime counteraction by the example of special services of
Ukraine and the CIS countries. Journal of Legal, Ethical and Regulatory Issues, Vol. 22 (1), 8 p., 2019.

[10] G.S. Panova. Cryptocurrency - Money of the Digital Economy. Lecture Notes in Networks and Systems. 2020. DOI: 10.1007/978-3-030-27015-5_72.

[11] A. Kwilinski. (2018). Mechanism of modernization of industrial sphere of industrial enterprise in accordance with requirements of the information economy. Marketing and Management of Innovations, Vol. 4, pp. 116-128, 2018. https://doi.org/10.21272/mmi.2018.4-11.

[12] A. Masharsky, G. Azarenkova, K. Oryekhova, and S. Yavorsky. Anti-crisis financial management on energy enterprises as a precondition of innovative conversion of the energy industry: case of Ukraine. Marketing and Management of Innovations, Vol. 3, pp. 345-354, 2018. https://doi.org/10.21272/mmi.2018.3-31

[13] R. Houben, A. Snyers (2018) Cryptocurrencies and blockchain. Legal context and implications for financial crime, money laundering and tax evasion. 2018. URL: http://www.euro

parl.europa.eu/cmsdata/150761/TAX3\%20Study\%20on\%20 cryptocurrencies\%20and\%20blockain.pdf.

[14] I.N. Efremenko, T.V. Panasenkova, D.A. Artemenko, and V.A. Larionov. The role of crypto-currencies in the development of the global currency system. European Research Studies Journal, Vol. 21 (1), pp. 117-124, 2018.

[15] J. Surowiecki. Bitcoin would be a calamity, not an economy. Technology Review, Vol. 121 (3), pp. 28-31, 2018. [16] A. Kulish, N. Andriichenko, and O. Reznik. A step forward in the minimization of political corruption in financial support of political parties: The experience of Ukraine and Lithuania. Baltic Journal of Law and Politics. 2018. DOI: 10.2478/bjlp-2018-0005.

[17] R. White, Y. Marinakis, N. Islam, and S. Walsh. Is Bitcoin a currency, a technology-based product, or something else? Technological Forecasting and Social Change, 2020. DOI: 10.1016/j. techfore.2019.119877.

[18] V.A. Galanov, D.G. Perepelitsa, A.V. Galanova, N.F. Chelukhina, and E.A. Asyeva. The concept and models of the cryptocurrency market. International Journal of Engineering and Technology (UAE), Vol. 14, pp. 311-315, 2018.

[19] L. Cocco, R. Tonelli, and M. Marchesi. (2019) An agent based model to analyze the bitcoin mining activity and a comparison with the gold mining industry. Future Internet, 2019. DOI: $10.3390 /$ fil 1010008 .

[20] T. Vasilyeva, L. Sysoyeva, and A. Vysochyna (2016). Formalization of factors that are affecting stability of ukraine banking system. Risk Governance and Control: Financial Markets and Institutions, Vol. 6(4), pp. 7-11. doi:10.22495/rcgv6i4art1.

[21] T.A. Vasylyeva, S.V. Leonov, and O.V. Lunyakov. Countercyclical capital buffer as a macroprudential tool 
for regulation of the financial sector. Actual Problems of Economics, Vol. 158(8), pp. 278-283, 2014.

[22] G. Tziakouris. Cryptocurrencies - A forensic challenge or opportunity for law enforcement? An INTERPOL perspective IEEE Security and Privacy, 2018. DOI: 10.1109/MSP.2018. 3111243).

[23] Volosovych S., Baraniuk Y. (2018) Tax control of cryptocurrency transactions in Ukraine. Banks and Bank Systems. DOI: 10.21511/bbs.13 (2).2018.08

[24] E. L. Moreva. Ventrue capital in Russia and the global evolution of venture capital. Journal of Reviews on Global Economics, Vol 7, 2018, pp. 843-850. DOI: 10.6000/1929-7092.2018.07.

[25] A.J. Ram. Taxation of the Bitcoin: initial insights through a correspondence analysis. Meditari Accountancy Research, 2018. DOI: 10.1108/MEDAR-10-2017-0229.

[26] L.F. Kjaersgaard, A. Arfwidsson. Taxation of Cryptocurrencies from the Danish and Swedish Perspectives. Intertax, Vol. 47 (6-7), pp. 620-634, 2019.

[27] J. Chiu and Th. Koeppl (2017) The Economics of Cryptocurrencies - Bitcoin and Beyond. Chapman University. $40 \mathrm{p}$.

https://doi.org/10.2139/ssrn.3048124

[28] Decree of the President of the Republic of Belarus On Digital Economy Development. URL: http://president.gov.by/ru/official_documents_ru/view/dekret 8ot21dekabrja2017g 17716.

[29] V. Korniev, and O. Cheberiako. Cryptocurrencies: the era and scope of financial transactions. Bulletin of Taras Shevchenko National University of Kyiv. Economics, Vol. 1 (196), pp. 40-46, 2018.

[30] Rzeczpospolita polska Minister rozwoiu i finansow. URL: http://orka2.sejm.gov.pl/ INT8.nsf/klucz/658C47ED/ $\%$ 24FILE/i06655-o1.pdf.

[31] A. Berentsen, and F. Schär. A Short Introduction to the World of Cryptocurrencies. Federal Reserve Bank of St. Louis Review, Vol. 100 (1), pp. 1-16, 2018.

https://doi.org/10.20955/r.2018.1-16

[32] STABLECOINS An overview of the current state of stablecoins $\quad$ URL: https://download.blockdata. tech/blockdata-stablecoin-report-blockchain-technology.pdf 